\title{
Research on User Requirements of Ergonomic Innovation Experiment Platform Based on Kano Model
}

\author{
Yang Lifang ${ }^{1, a^{*}}$, Wang Jiaqi ${ }^{2, b}$
}

\author{
${ }^{1}$ Harbin Institute of Technology, Harbin, China \\ ${ }^{2}$ Harbin Institute of Technology, Harbin, China \\ $a^{*}$ Corresponding author. Email: ycub@163.com \\ b568278500@qq.com
}

\begin{abstract}
Harbin Institute of Technology offers the innovation experiment course of ergonomics at undergraduate stage. This course enables students to understand and master the basic concept, basic principle and basic method of ergonomics, at the same time, master the method of how to use the experimental equipment of ergonomics, combine the classroom teaching with practice, and guide students to engage in the scientific research of ergonomics and application practice activities. Through user interview and questionnaire survey on student users, based on the Carnot model, the user requirements of the ergonomic innovation experiment platform are studied, and the functional and non-functional requirements of the ergonomic innovation experiment teaching platform are determined, so that the specific design objectives of the ergonomic innovation experiment teaching platform can be further proposed, and the main functional modules of the platform can be determined Good at human-machine engineering innovation experiment teaching platform.
\end{abstract}

Keywords: ergonomics, Carnot analysis, experimental teaching platform, demand determination

\section{INTRODUCTION}

Kano model analysis method is a set of structural questionnaire and analysis method developed by Ono Jizhao based on the subdivision principle of Kano model for user needs[1]. Kano model analysis method is mainly through standardized questionnaire survey, according to the survey results to classify the attributes of various factors, to solve the positioning problem of product attributes, in order to improve customer satisfaction[2]. Based on the Carnot model, it is necessary to determine the user needs of the human-machine engineering innovation experiment platform. After sorting out the original requirements of users for the platform, summarize and conclude, and determine the requirements for Carnot analysis. Finally, the key factors influencing the innovation experiment platform of human-machine engineering are analysed by using Carnot model[3].

\section{DETERMINATION OF RESEARCH NEEDS}

\subsection{Preliminary demand determination}

The first is to determine the initial user demand index. The in-depth interview was conducted to the students who have studied or will study the human-machine engineering experiment course in Harbin Institute of technology[4].

After the interview, the questions answered by the interviewees were summarized and sorted out. A total of 20 users' original demand descriptions for the needs of the ergonomic innovation experiment teaching platform were proposed and extracted. The demand extraction of the interview results is shown in the following table.

Table 1 Initial demand

\begin{tabular}{|c|c|c|}
\hline Serial number & Demand extraction & Requirement description \\
\hline 1 & Pre-learning & $\begin{array}{r}\text { The video for the use of experimental equipment is provided on the } \\
\text { experimental platform; }\end{array}$ \\
& $\begin{array}{r}\text { The teaching video can be downloaded; } \\
\text { Watch the teaching video by using the fragment time; } \\
\end{array}$ & $\begin{array}{c}\text { On the experimental platform, there are text descriptions of operation } \\
\text { steps and notes; } \\
\text { Text introduction of the purpose, content and method of the experiment. }\end{array}$ \\
\hline
\end{tabular}




\begin{tabular}{|c|c|c|}
\hline 2 & $\begin{array}{l}\text { Experimental data } \\
\text { input and processing }\end{array}$ & $\begin{array}{l}\text { Data input is carried out in the experiment class, and the experiment } \\
\text { conclusion is written after class; } \\
\text { After data entry, the platform can directly process the data into visual } \\
\text { images; } \\
\text { Process the experimental data according to the selection (such as } \\
\text { average, range, etc.). }\end{array}$ \\
\hline 3 & $\begin{array}{l}\text { Generate experiment } \\
\text { report }\end{array}$ & $\begin{array}{l}\text { The platform can automatically generate experimental reports; } \\
\text { The platform provides electronic experimental report; }\end{array}$ \\
\hline 4 & $\begin{array}{l}\text { Smooth video } \\
\text { playback }\end{array}$ & Teaching videos are loaded quickly \\
\hline 5 & Query results & $\begin{array}{c}\text { You can query the experimental results; } \\
\text { Check the results and see the results of each experiment. }\end{array}$ \\
\hline 6 & $\begin{array}{l}\text { Comprehensive } \\
\text { ability evaluation }\end{array}$ & $\begin{array}{l}\text { According to the experimental data, the model of operation ability is } \\
\text { obtained. }\end{array}$ \\
\hline 7 & $\begin{array}{l}\text { Compatible mobile } \\
\text { mode }\end{array}$ & $\begin{array}{l}\text { It is more convenient to use mobile phones to record data in class; } \\
\text { Watching the teaching video with mobile phone. }\end{array}$ \\
\hline 8 & Exchange of learning & $\begin{array}{c}\text { Ask the teacher questions on the platform; } \\
\text { You can ask the elder and elder sisters who have already taken this } \\
\text { course through the platform. }\end{array}$ \\
\hline 9 & $\begin{array}{c}\text { Automatic } \\
\text { preservation }\end{array}$ & $\begin{array}{l}\text { Before the experimental report is submitted, the filled contents shall be } \\
\text { saved immediately. }\end{array}$ \\
\hline 10 & Modifiable & The submitted report can be modified before the teacher gives the score. \\
\hline
\end{tabular}

\subsection{Final demand determination}

Curriculum user demand is the basis for the evaluation of online curriculum quality, so the evaluation standard of online curriculum can provide some reference for the determination of curriculum user demand index[5]. The index that can provide reference for the user demand of ergonomic innovation experiment teaching platform is summarized as follows: (1) Course content (teaching design, teaching content, learning resources, etc.). (2) Interaction (interface design, color design, interaction process design, etc.). (3) Learning process (learning process, curriculum design, function design, etc.). (4) Technology application (database, technicality, backstage support system, etc.).

Corresponding to the requirements obtained from the interview and the index system, it can be concluded that prelearning belongs to the requirements of the course content, the entry and processing of experimental data, the smoothness of the video, the comprehensive ability evaluation model, and the requirements for the use of compatible mobile phones are technical requirements, and generate experimental reports, Query results, learning exchanges, auto-save, after saving, you can change the needs that are part of the interaction and learning process[6].

\section{RESEARCH ON USER DEMAND OF ERGONOMIC INNOVATION EXPERIMENTAL PLATFORM BASED ON KANO MODEL}

\subsection{Introduction of Kano Model}

Kano model defines three levels of customer demand: basic demand, expected demand and excited demand. These three kinds of needs are classified into basic factors, performance factors and incentive factors according to performance indicators[7].

Kano model analysis method is a set of structural questionnaire and analysis method developed by Ono Jizhao based on the subdivision principle of Kano model for customer demand. Kano model analysis method is not directly used to measure customer satisfaction. It is mainly used to identify customer needs, help enterprises understand different levels of customer needs, and determine the key elements of customer satisfaction[8].

Kano model analysis method needs to collect additional survey information according to the structural questionnaire designed by Ono Jizhao. The basic steps are as follows. 
(1) Understand the needs of products / services from the perspective of customers; (2) Design questionnaire; (3) Implement effective questionnaire survey; (4) Classify and summarize the survey results, and establish the quality prototype; (5) Analyse the quality prototype and identify the sensitivity of specific measurement indicators[9].

In order to be able to distinguish quality characteristics into basic needs, expectation needs, and charm needs, each quality characteristic in the KANO questionnaire is composed of two questions, positive and negative, to measure whether the customer is facing a certain existence or not Response to quality characteristics. The answers to the questions in the questionnaire generally use five levels of options, which are "like", "should be", "indifferent", "tolerable", and "dislike" [10]. With this appropriate scale, the questionnaire will be more reliable. For each answer level used in the questionnaire, the classification of quality attributes is different[11].

\subsection{Introduction of Kano Model}

Using the KANO model analysis method to identify user needs, after obtaining data for each quality characteristic through investigation, it is possible to calculate the frequency of each quality characteristic appearing in different demand types. Through the questionnaire survey of 140 college students, the frequency of various quality characteristics can be obtained.
In the classification, the data of $\mathrm{I}, \mathrm{R}$, and $\mathrm{Q}$ need not be considered, and the classification result of the quality characteristic is determined according to the frequency of each quality characteristic appearing in $\mathrm{A}, \mathrm{O}$, and $\mathrm{M}$. As can be seen from the table, the two functional requirements of video and forum are charm requirements. Without these functions, users are generally unconscious, but having these functions may make users shine. The four functional requirements of data entry, data processing, query results, and picture and text are basic requirements. They are not intentionally emphasized in normal communication, but these functions will be complained once they are not available. Generate reports, smooth videos, compatible with mobile phones, automatic save, submit and modify the five requirements.

The analysis of the KANO model is to analyse the satisfaction and dissatisfaction of each quality characteristic to determine the customer's sensitivity to changes in the level of these quality characteristics, and then determine the improvement of those quality characteristics that are highly sensitive and more conducive to customer satisfaction. First, the satisfactory influence (SI) and unsatisfactory influence (DSI) are calculated. The calculation formula is as follows:

$$
\begin{aligned}
& S I=(A+O) /(A+O+M+I) \\
& D S I=-1 \times(O+M) /(A+O+M+I)
\end{aligned}
$$

Using the above formula to calculate the example, the results are as follows.

Table 2 Functional sensitivity analysis results

\begin{tabular}{|c|c|c|}
\hline Quality characteristics & $\mathbf{S I}=\mathbf{( A + O )} /(\mathbf{A}+\mathbf{O}+\mathbf{M}+\mathbf{I})$ & $\mathbf{D S I}=\mathbf{- 1} \times(\mathbf{O}+\mathbf{M}) /(\mathbf{A}+\mathbf{O}+\mathbf{M}+\mathbf{I})$ \\
\hline Video & 0.61 & -0.50 \\
\hline Data entry & 0.46 & -0.54 \\
\hline Data processing & 0.50 & -0.50 \\
\hline Generate report & 0.82 & -0.65 \\
\hline Video smoothing & 0.61 & -0.52 \\
\hline Query results & 0.48 & -0.23 \\
\hline Comprehensive evaluation & 0.50 & -0.19 \\
\hline Compatible mobile phone & 0.25 & -0.48 \\
\hline Automatic preservation & 0.71 & -0.18 \\
\hline Forum & 0.73 & -0.48 \\
\hline Submit revision & 0.70 & -0.65 \\
\hline Picture text & 0.39 & \\
\hline
\end{tabular}

The mass characteristics are put into sensitivity matrix with Si value as abscissa and DSI value as ordinate. Factors other than the radius circle (the circle with the origin 0 as the centre and OP as the radius in the figure below), and the farther away from the origin, the greater the sensitivity. 


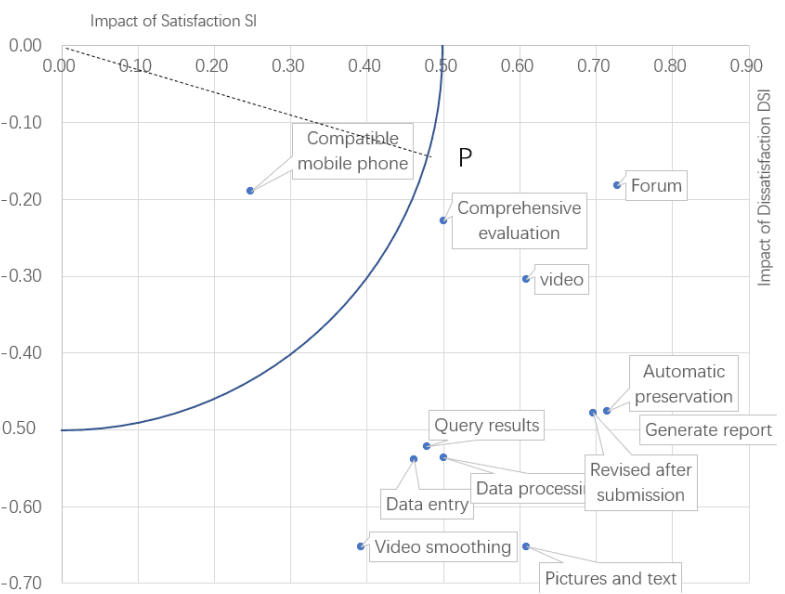

Figure 1 Kano model analysis results

From the above figure, it can be determined that the image text and video are smooth, submitted for modification, automatically saved, and the point of report generation is far away from the origin, and the quality characteristics are highly sensitive. Making these functions is more conducive to improving user satisfaction. The premise of realizing the video fluency function is to have video function, which means that if we want to experiment the video function with low sensitivity of quality characteristics, we also need to meet the video fluency function with high sensitivity of quality characteristics. However, the quality characteristics of compatible mobile phone functions in the circle are not sensitive, which can be ignored temporarily.

\section{CONCLUSION}

In this paper, through questionnaire and user interviews, based on the Carnot model, the requirements of humanmachine engineering innovation experiment platform are studied. After summarizing the user requirements of the platform, the functional and non-functional requirements are determined by referring to the evaluation standard of the network course, and then the main functional modules of the platform are obtained. After obtaining the data of each quality characteristic through investigation, calculate the frequency of each quality characteristic in different demand types, and determine the functional demand types. Kano model was used to analyse the influence of satisfaction and dissatisfaction on quality characteristics. Judge the sensitivity of users to the level change of these quality characteristics. Finally, the research concludes that the four functional requirements of data entry, data processing, query results, pictures and text are basic requirements, and the quality characteristics are highly sensitive. Compatible mobile phone is not sensitive to this feature quality, which can be ignored. After meeting the basic functional requirements, other functions can be added to the platform.

\section{REFERENCES}

[1] Zhong Deqiang, Huang Ying. Refrigerator personalized demand analysis based on Kano model $[\mathrm{J}]$. Journal of Hunan University of Technology (SOCIAL SCIENCE EDITION), 2019,24 (02): 48-53.

[2] Wang Shuang, Yin Guofu, He Zhongxiu. Research on user demand index system based on Kano model [J]. Packaging Engineering, 2006 (04): 209-210 + 213.

[3] Meng Qingliang, Jiang Xiujun. Method for determining the final importance of customer demand based on quantitative KANO model [J]. Statistics and Decision, 2012 (06): 32-35.

[4] Lu Zhaolin, Tang Wencheng. Research progress of ergonomics theory, technology and application in industrial design $[\mathrm{J}]$. Journal of engineering graphics, 2009,30 (06): 1-9

[5] Wang Chen, Zhao Wu, Wang Jie, Chen Ling. Multidimensional user demand acquisition based on ontology $[\mathrm{J}]$. Computer Integrated Manufacturing Systems, 2016, 22 (04): 908-916.

[6] Five styles of customer knowledge management and how smart company use them to create value. Michael Gibbert,Marius Leibold,Gilbert Ptobst. European Management Journal . 2002.

[7] Yuan Yue, Hou Wenjun. Research on the Application of Kano Model in Internet User Experience_-Taking a Mobile Phone Search Client Functional Requirement Analysis as an Example [J]. Software, 2013, 34 (04): 74-78.

[8] Liu Fei. Seven principles to help you distinguish the authenticity of "user demand" [J]. China storage and transportation, 2019 (09): 107.

[9] Laura Južnik Rotar, Mitja Kozar. The Use of the Kano Model to Enhance Customer Satisfaction. 2017, 50 (4): 339-351.

[10] Long Yuling. Research on personalized demand acquisition method based on Kano model [D]. Central South University, 2011

[11] Larissa Rodrigues Barcellos Martins,Lucas de Sant'Anna Pereira,Luana Maravilha de Almeida,Henrique Rego Monteiro da Hora,Helder Gomes Costa. Study on the most appropriate scale for use in questionnaires: an experiment with Kano's model Estudo sobre escala mais adequada em questionários: um experimento com o modelo de Kano[J]. Vértices,2011,13(1). 